\title{
JECH
}

\section{Class-related health inequalities are not larger in the East: a comparison of four European regions using the new European socioeconomic classification}

T A Eikemo, A E Kunst, K Judge and J P Mackenbach

J Epidemiol Community Health 2008;62;1072-1078; originally published online 15 Apr 2008;

doi:10.1136/jech.2007.072470

Updated information and services can be found at:

http://jech.bmj.com/cgi/content/full/62/12/1072

These include:

Data supplement

"web only table"

http://jech.bmj.com/cgi/content/full/jech.2007.072470/DC1

References This article cites 18 articles, 8 of which can be accessed free at:

http://jech.bmj.com/cgi/content/full/62/12/1072\#BIBL

Rapid responses You can respond to this article at:

http://jech.bmj.com/cgi/eletter-submit/62/12/1072

Email alerting Receive free email alerts when new articles cite this article - sign up in the box at service the top right corner of the article

Notes

To order reprints of this article go to:

http://journals.bmj.com/cgi/reprintform

To subscribe to Journal of Epidemiology and Community Health go to:

http://journals.bmj.com/subscriptions/ 


\title{
Class-related health inequalities are not larger in the East: a comparison of four European regions using the new European socioeconomic classification
}

\author{
T A Eikemo, ${ }^{1,2}$ A E Kunst, ${ }^{2}$ K Judge, ${ }^{3}$ J P Mackenbach ${ }^{2}$
}

- An additional table is published online only at http:// jech.bmj.com/content/vol62/ issue12

${ }^{1}$ Department of Sociology and Political Science, Norwegian University of Science \& Technology and SINTEF Health Research, Norway;

${ }^{2}$ Department of Public Health, Erasmus University Medical Centre, Rotterdam, The Netherlands; ${ }^{3}$ School for Health, University of Bath, Bath, UK

Correspondence to:

Dr T A Eikemo, SINTEF Health

Research, 7465 Trondheim,

Norway; Terje.A.Eikemo@

sintef.no

Accepted 3 March 2008

Published Online First

15 April 2008

\begin{abstract}
Background: The article investigates whether people in Eastern Europe have larger health inequalities than their counterparts in three West European regions (North, Central and the South).
\end{abstract}

Methods: Data were obtained for 63754 individuals in 23 countries from the first (2002) and second (2004) waves of the European Social Survey. The health outcomes were self-reported limiting longstanding illness and fair/poor general health. Occupational class was defined according to the European Socioeconomic Classification (ESeC). The magnitude of absolute and relative inequalities according to nine occupational classes for men and women separately were identified, analysed and compared in all four regions of Europe.

Results: For both sexes and within all European regions, the higher and lower professionals, self-employed and higher service workers reported fewer cases of ill health than other occupational classes. In contrast, lower technical and routine workers reported the poorest health, excluding the relatively small number of farmers. Income and education did not explain more, or less, of the classrelated health inequalities in the East compared with the other regions.

Conclusions: Little evidence was found for the hypothesis that East European countries have larger classrelated health inequalities than other European regions. People's income and educational attainment both contribute to occupational health inequalities in the East as well as in the West.

Substantial differences in average life expectancy have been reported between the Eastern and Western European populations since the end of the communist era, ${ }^{1-4}$ but little is known about health inequalities in the East compared to West. The few studies available for Eastern Europe have only looked at inequalities in relationship to educational level..$^{5-8}$ These studies suggest that inequalities in mortality are probably larger in the East than in Western European countries, but there is no evidence so far suggesting larger inequalities in morbidity in the East; the few available studies did not systematically compare the East and the West. ${ }^{9-12}$

The overall aim of the present article is to compare class-related health inequalities in selfassessed health within six East European countries and 17 West European countries by applying the new European Socioeconomic Classification (EseC) scheme on the European Social Survey. Class is regarded as a good predictor of health in both West and East European countries. ${ }^{13}$ With ESeC, problems of comparability have now been addressed to a much larger extent than in any previous occupational class scheme. We aim to examine the magnitude of absolute and relative health outcomes in the East with regard to nine occupational classes for men and women separately, which are compared with inequalities observed in three West European subregions (North, Central and South), covering 17 European countries. This categorisation is based on a priori reasons. The main distinction is made between "East" and other countries, with countries being allocated to the "East" group in a commonly applied way ${ }^{8-10} 14$ that is derived from historical and political factors (e.g. communist rule) and epidemiological commonalities (e.g. clearly lower life expectancies). The analysis involves three steps. First we describe class patterns in nine occupational groups in the East and the West. West European countries are further classified into three subregions: the North, Central and South. Second, we aim to compare the magnitude of health inequalities in the East with those observed in the West, both in absolute and relative terms. The third intention is to investigate whether the contributions of education and income to class-related health inequalities in the East differ from those in the West.

\section{DATA AND METHODS}

The data source is made up of two independent waves of the European Social Survey (merged files from 2002 and 2004), from which we analysed 63754 individuals (aged 25 years or more) from 23 countries (table 1). The two health outcome variables were self-reported limiting longstanding illness and fair/poor general health. Occupational class was defined according to ESeC, which is a further development of the widely applied EriksonGoldthorpe-Portocarero classification. ${ }^{15}$ The ESeC classifies people according to their positions within labour markets and production units, with special attention to their employment relations. ESeC is designed to facilitate international overviews and cross-national comparisons across the EU. In order to improve population coverage, those who are not currently in paid employment are allocated to an ESeC class on the basis of their last main paid job (see table 2). Most analyses distinguish all nine available classes, although a summary measure comparing classes 1 and 2 with classes 8 and 9 was constructed for some analyses.

The distribution of respondents in nine occupational classes by gender and region is presented in 
Table 1 Response rates and total number of respondents (by gender and country) for the first two waves (2002 and 2004) of the European Social Survey

\begin{tabular}{|c|c|c|c|c|c|c|c|c|c|}
\hline \multirow[b]{3}{*}{ Region } & \multirow[b]{3}{*}{ Country } & \multicolumn{4}{|c|}{2002} & \multicolumn{4}{|c|}{2004} \\
\hline & & \multirow[b]{2}{*}{ Response rate (\%) } & \multicolumn{3}{|c|}{ Included in the analysis } & \multirow[b]{2}{*}{ Response rate (\%) } & \multicolumn{3}{|c|}{ Included in the analysis } \\
\hline & & & Men & Women & Total & & Men & Women & Total \\
\hline & Estonia & & & & & 79.1 & 643 & 981 & 1624 \\
\hline & Hungary & 69.9 & 508 & 726 & 1234 & 65.4 & 660 & 691 & 1351 \\
\hline & Poland & 73.2 & 635 & 660 & 1295 & 73.7 & 776 & 796 & 1572 \\
\hline \multirow[t]{6}{*}{ West (North) } & Denmark & 67.7 & 609 & 642 & 1251 & 64.3 & 658 & 617 & 1275 \\
\hline & Finland & 73.2 & 803 & 901 & 1704 & 70.7 & 797 & 846 & 1643 \\
\hline & Norway & 65.0 & 779 & 731 & 1510 & 66.2 & 962 & 811 & 1773 \\
\hline & Sweden & 69.5 & 831 & 817 & 1648 & 65.9 & 863 & 828 & 1691 \\
\hline & Ireland & 64.5 & 730 & 910 & 1640 & 59.7 & 708 & 760 & 1468 \\
\hline & United Kingdom & 55.5 & 753 & 772 & 1525 & 54.6 & 839 & 881 & 1720 \\
\hline & Luxembourg & 43.9 & 678 & 546 & 1224 & 50.1 & 496 & 497 & 993 \\
\hline & Netherlands & 67.9 & 701 & 889 & 1590 & 65.1 & 911 & 1053 & 1964 \\
\hline & Switzerland & 33.5 & 833 & 941 & 1774 & 48.6 & 821 & 836 & 1657 \\
\hline \multirow[t]{4}{*}{ West (South) } & Greece & 80.0 & 900 & 867 & 1767 & 78.8 & 921 & 850 & 1771 \\
\hline & Italy & 43.7 & 437 & 396 & 833 & & & & \\
\hline & Portugal & 68.8 & 639 & 763 & 1402 & 71.2 & 533 & 604 & 1137 \\
\hline & Spain & 53.2 & 604 & 462 & 1066 & 59.7 & 565 & 494 & 1059 \\
\hline
\end{tabular}

table 2. It shows that the populations in the East have similar class distributions to the other regions, with one main exception. The percentage of lower technical and routine workers is much larger in the East than elsewhere except for South European women. In the South, the percentage of selfemployed and farmers is much larger, and the percentage of higher and lower professional workers is much lower than elsewhere.

Education was measured as years of full-time education completed, whereas income was based on household income. In the ESS the respondents were shown a card, on which 12 weekly, monthly and annual wage intervals were given, each marked with a letter. The respondents were then asked: "Using this card, if you add up the income from all sources, which letter describes your household's total net income? If you don't know the exact figure, please give an estimate. Use the part of the card that you know best: weekly, monthly or annual income". From this variable, we constructed a scaled variable based on the median (average of lower and upper limit) value of these intervals, which in turn was recoded into a weekly equivalent income variable, using the OECD-modified scale. This scale assigns a value 1 to the household head, 0.5 to each additional adult member and 0.3 to each child. ${ }^{16}$ The variable was recoded into country-specific tertiles (four categories alltogether, of which non-respondents on income were included as a dummy variable on their own). We also tested whether this rather broad categorisation might underestimate the contribution of income in explaining health-related class inequalities in the East by applying income quintiles instead of tertiles, but this strategy gave similar results to those presented in table 3 .

Prevalence rates and absolute differences were calculated using direct age standardisation. Relative health inequalities were calculated applying a series of logistic regression analyses. Table 2 was based on logistic regression analysis, in which class

Table 2 The distribution of respondents in nine occupational classes by gender and region $(N=63754)$

\begin{tabular}{|c|c|c|c|c|c|c|c|c|c|c|c|c|}
\hline Sex & Region & $\begin{array}{l}\text { Higher } \\
\text { profession } \\
(\%)\end{array}$ & $\begin{array}{l}\text { Lower } \\
\text { profession } \\
(\%)\end{array}$ & Service $(\%)$ & $\begin{array}{l}\text { Self-employed } \\
(\%)\end{array}$ & $\begin{array}{l}\text { Farmers } \\
\text { etc. }(\%)\end{array}$ & $\begin{array}{l}\text { Supervisors } \\
(\%)\end{array}$ & $\begin{array}{l}\text { Sales } \\
(\%)\end{array}$ & $\begin{array}{l}\text { Lower } \\
\text { technical } \\
(\%)\end{array}$ & Routine & $\mathbf{N}$ & $\begin{array}{l}\text { Missing } \\
(\%)\end{array}$ \\
\hline \multirow[t]{4}{*}{ Men } & East & 10.1 & 14.7 & 3.2 & 8.6 & 3.1 & 12.3 & 5.1 & 21.2 & 21.6 & 6316 & 4.0 \\
\hline & North & 17.2 & 19.6 & 3.7 & 10.4 & 3.8 & 13.3 & 4.1 & 12.5 & 15.3 & 9331 & 0.5 \\
\hline & Central & 17.4 & 23.2 & 6.0 & 8.0 & 2.4 & 14.5 & 4.6 & 12.1 & 11.8 & 10893 & 1.0 \\
\hline & South & 9.5 & 11.8 & 4.7 & 17.8 & 9.5 & 10.2 & 5.2 & 15.0 & 16.2 & 4599 & 2.7 \\
\hline \multicolumn{2}{|c|}{ Based on last job* } & 20.4 & 23.9 & 25.0 & 17.9 & 20.4 & 28.9 & 30.7 & 35.0 & 35.9 & & \\
\hline \multirow[t]{4}{*}{ Women } & East & 7.2 & 22.9 & 15.4 & 5.5 & 2.3 & 6.0 & 15.4 & 5.8 & 19.6 & 7155 & 5.0 \\
\hline & North & 7.9 & 25.2 & 14.7 & 4.5 & 0.9 & 7.3 & 19.9 & 2.9 & 16.7 & 9516 & 2.0 \\
\hline & Central & 7.6 & 26.0 & 19.4 & 4.9 & 0.9 & 6.1 & 15.2 & 3.8 & 16.1 & 11507 & 3.5 \\
\hline & South & 4.6 & 12.6 & 10.1 & 11.2 & 8.2 & 4.3 & 11.9 & 8.5 & 28.5 & 4436 & 12.9 \\
\hline \multicolumn{2}{|c|}{ Based on last job* } & 28.0 & 33.2 & 41.0 & 32.5 & 43.2 & 42.4 & 47.4 & 65.0 & 57.7 & & \\
\hline
\end{tabular}

\footnotetext{
${ }^{*}$ Occupational class was allocated on the basis of last rather than current job
} 
Table 3 Class-related health inequalities (OR, 95\% Cl) after control for age (model 1), age + education (model 2), age + income (model 3), and age + education + income (model 4) by gender in four European regions

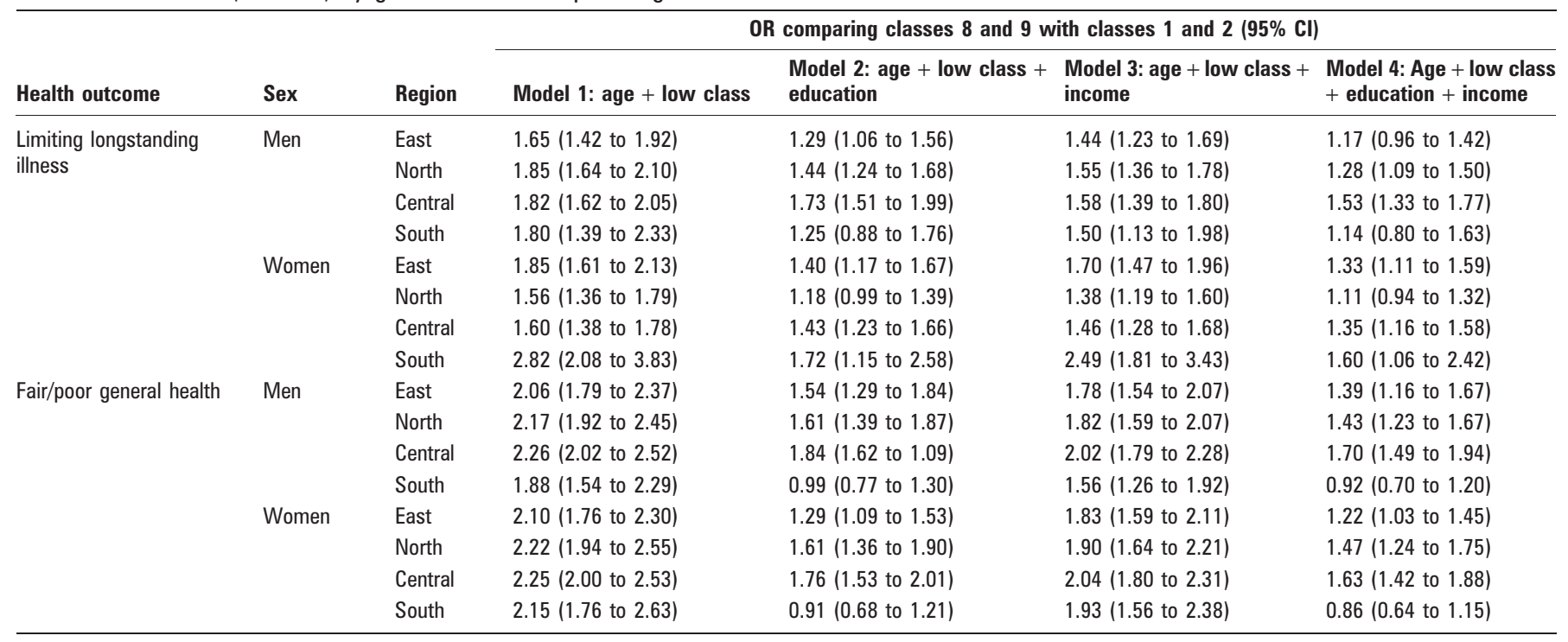

was introduced with eight category-independent variables (using higher professionals as the reference category), controlled for age, with health outcomes as the dependent variables. The results shown in Table 3 were based on the summary measure of class. In the basic model (model 1), class was introduced as an independent variable, controlled for age. In the second and third models, education and income were added to the model respectively, whereas the fourth model included all three measures of socioeconomic position. On this basis, we were able to calculate the independent contribution of education and income and their joint effect to class-related health inequalities.

The independent contribution of education to class-related health inequalities was calculated by the percentage reduction of the ORs of occupational class attributable to the inclusion of education (model 2) to the model already containing income tertiles (model 3). The independent contribution of income was calculated in the same manner, replacing education with income. The overlapping contribution of income and education was then calculated by subtracting the independent contribution of education (model 2) with the total (independent and indirect) contribution of income.

\section{RESULTS}

Figure 1 shows age-adjusted prevalence rates for limiting longstanding illness and fair/poor health by gender, occupational class and geographical region. The lines, which represent each of the four regions, demonstrate an increasing picture from the left to the right. This indicates that using ESeC the numerically "higher" occupational classes have higher prevalence rates of ill health than the numerically "lower" classes. Across all geographical regions, the absolute difference of the prevalence rates was about $10 \%$ between the four highest occupational classes compared with the four lowest throughout the regions. Thus, figure 1 shows that the absolute differences of ill health are not larger in the East than in Western regions.

The only exception is with respect to the quite large absolute differences of ill health among farmers in the East (class 5), but also among women in the North with respect to fair/poor general health. However, we should be careful in drawing too much attention to this finding, as the number of respondents is relatively few in this class. Figure 2 shows ORs for limiting longstanding illness and fair/poor health by occupational class, gender and geographical area. Generally, all regions were similar with regard to relative differences.

Furthermore, relatively large ORs of ill health were found among farmers in the East $(2<\mathrm{OR}<3)$ and among farmer women in the North (OR 6,5). With only one minor exception in the East, no health differences were observed between the four higher occupational classes, whereas they were large between the reference group and the five lower occupational classes. In the other regions, on the other hand, health inequalities were generally also present among the most advantaged occupational classes.

Table 3, first column, shows the overall magnitude of relative class differences in health by means of a summary measure, comparing classes $1+2$ versus $8+9$. In these terms, the East European region was similar to the other regions, both with regard to limiting longstanding illness and fair/poor general health. For example, for men in the East, the OR of limiting longstanding illness is 1.65 compared with $1.85_{\text {North }}, 1.82_{\text {Central }}$ and $1.80_{\text {South }}$ in the other regions, whereas the OR of poor/fair general health for women in the East is 2.10 as against $2.22_{\text {North, }}$ 2.25 Central and $2.15_{\text {South }}$ in the remaining regions.

This regional pattern did not substantially change after controlling for education (second model), income (third model) and both education and income (fourth model). Figure 3 quantifies the contribution of education and income to the health disparities by occupational class position. Figure 3 also presents the indirect contribution of income. Figure 3 shows that $60-80 \%$ of class-related health inequalities could be attributed to class variations in educational and income level in the East. This is approximately the same amount as in the North, while even less (only $50 \%$ ) could be explained in the Central-West, mainly because of the low proportion explained by educational attainment. In contrast, we could explain even more class inequalities in the South than in the East.

We also tested whether within-region variations are larger than between-region variations by means of ANOVA. This analysis (not presented in the tables) showed that only a very small part of the variance of ORs reflects differences between the European regions (6\% for men and 10\% for women), whereas the within-region variance accounts for the remaining 

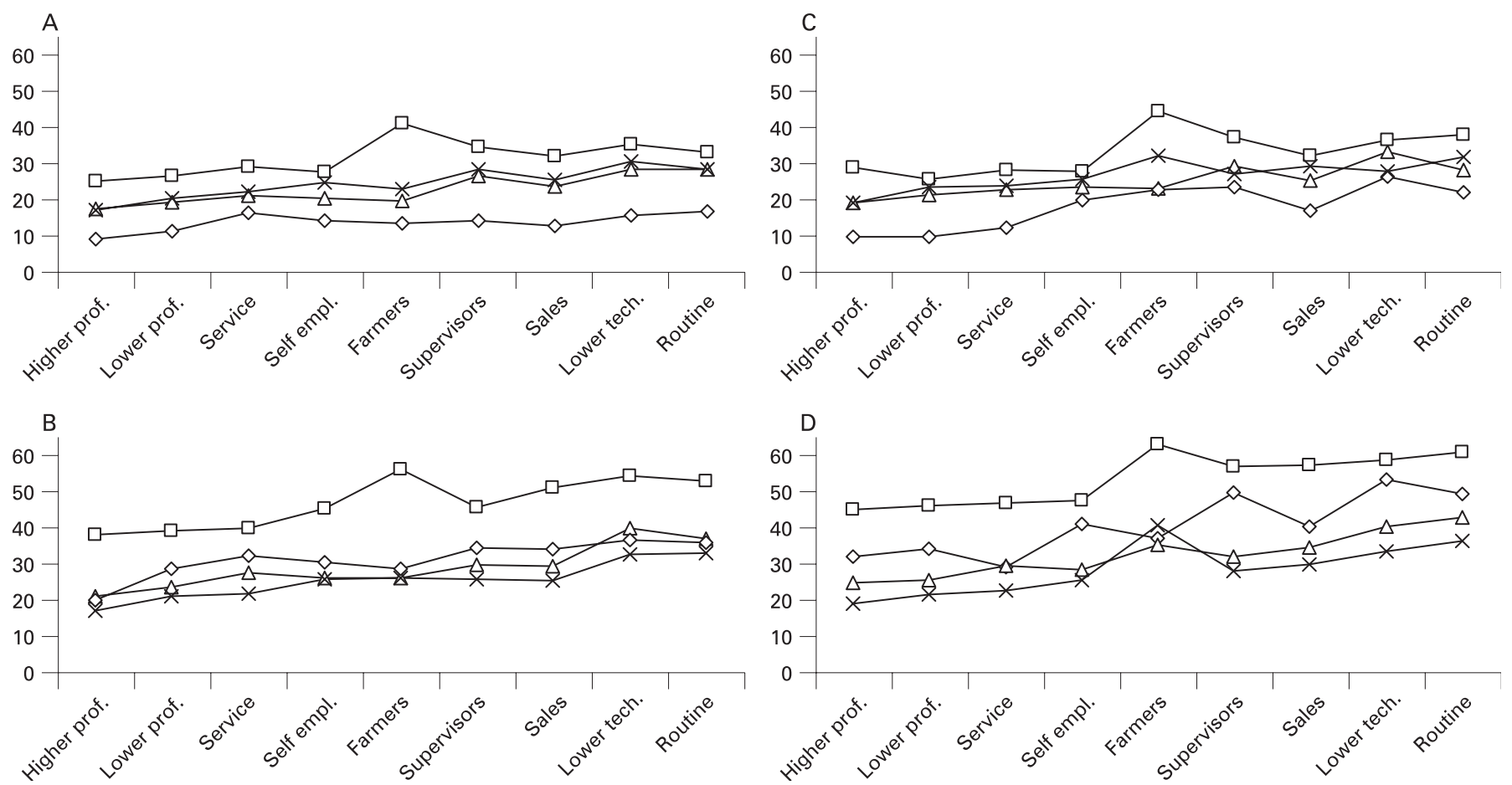

Figure 1 Age-adjusted prevalence rates (y-axis) of limiting longstanding illness and fair/poor general health in nine occupational classes ( $\mathrm{x}$-axis) for men and women. East $=\square$, North $=x$, Central $=\triangle$, South $=\diamond$. (A) Men's longstanding illness; (B) women's longstanding illness; (C) men's poor general health; (D) women's poor general health.
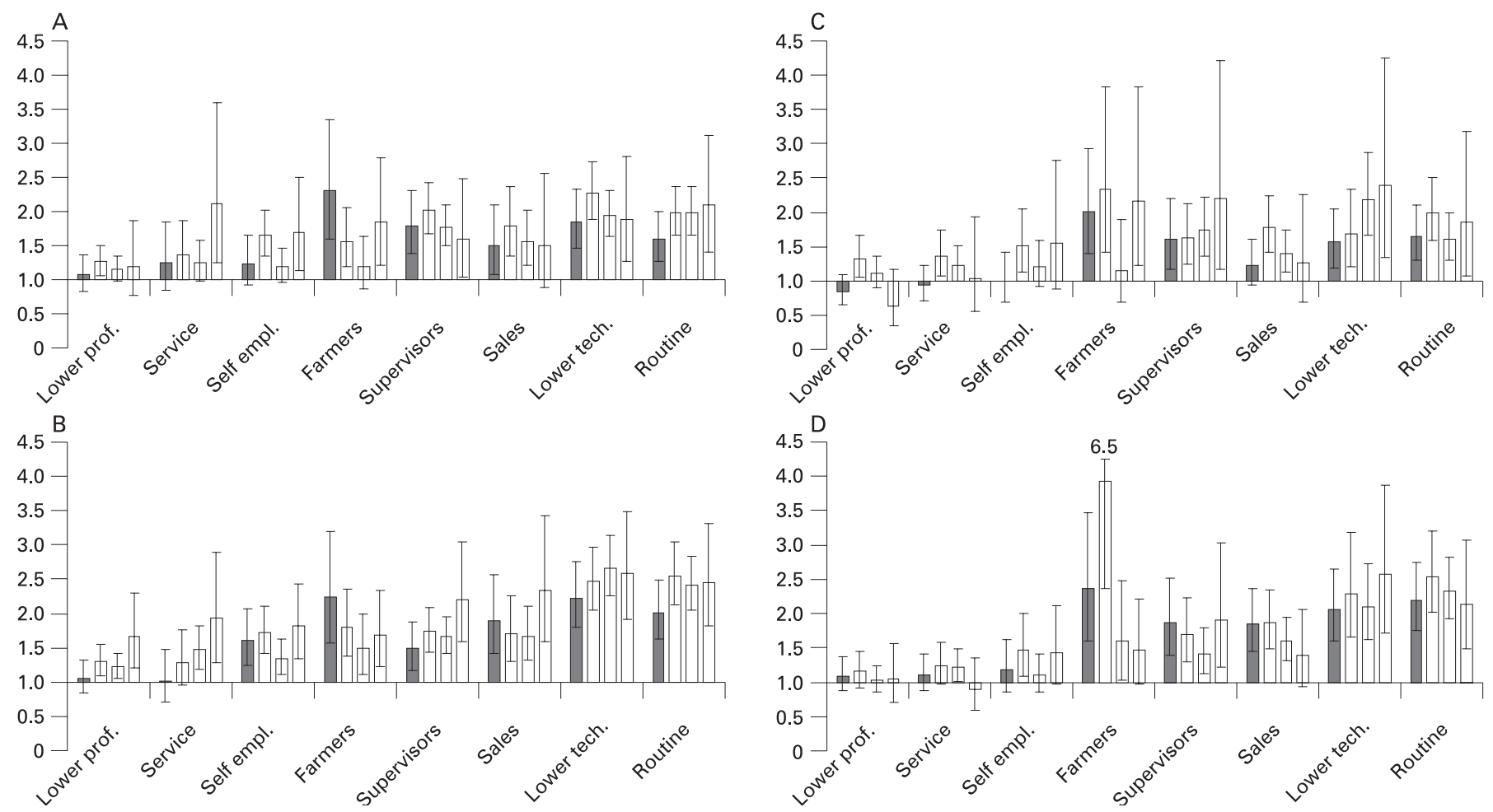

Figure 2 ORs (95\% Cl) for reporting limiting longstanding illness and poor health among men and women in nine occupational classes within the European regions East, North, Central and South (subsequently from the left to the right bars). (A) Men's longstanding illness; (B) women's longstanding illness; (C) men's poor general health; (D) women's poor general health. 


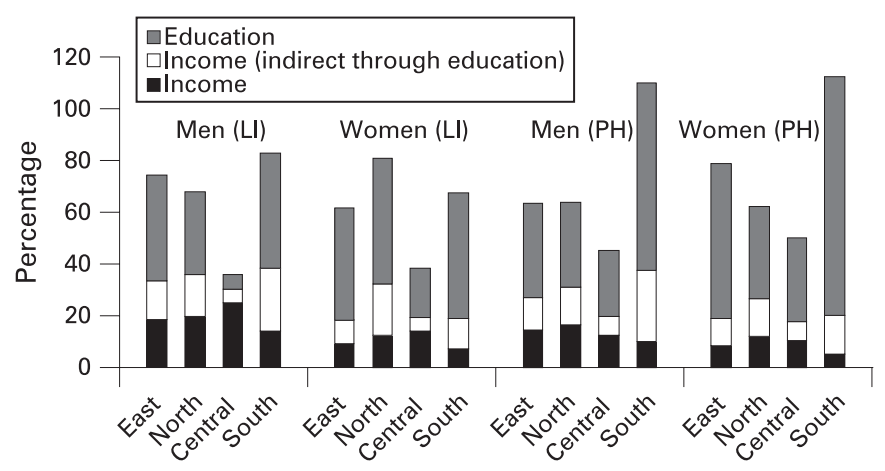

Figure 3 The independent contribution of education, income and their joint effect (income through education) in class-related health inequalities for men and women in East, North, Central and South Europe. These calculations are based on the three sets of regression models from Table 3: 1 , the independent contribution (\%) of education in class-related health inequalities [100*(Model 1-Model 4)/(Model 1-1)] - [100*(Model 1-Model 3)/(Model 1-1)]; 2, the independent contribution (\%) of income in class-related health inequalities [100*(Model 1-Model 4)/(Model 11)] - [100*(Model 1-Model 2)/(Model 1-1)]; 3, the indirect contribution (\%) of income through education [100*(Model 1-Model 2)/(Model 1-1)] $-\mathrm{A}$.

part. This indicates that the magnitudes of health inequalities are not systematically different between the two regions.

\section{DISCUSSION}

\section{Summary of findings}

This study provides little evidence in support of the hypothesis that East European countries have larger absolute or relative health inequalities in terms of self-reported morbidity than other European regions. For both sexes and within all European regions, the higher and lower professionals, self-employed and higher service workers reported fewer cases of ill health than other occupational classes. In contrast, lower technical and routine workers had the poorest health in this study. Farmers reported most cases of ill health, but the number of respondents is relatively low in this class. Finally, both education and income contribute independently to class-related health inequalities in the East and the West.

\section{Evaluation of data problems}

Some possible limitations of the study that could influence the observed East-West patterns should be addressed in more detail. The first concerns the missing information on occupational class for South European women (12.9\%). The question is whether they have the same level of health as the occupational class to which they are assigned. This is unlikely to have affected our results substantially, as our income data showed that these women do not report systematically different health status compared with other women (with known occupation) within the same income tertiles (not presented in tables). South European women whose occupation was known reported better health than the women who did not report an occupation. The difference was $7.6 \%$ versus $8.1 \%$ for fair/poor general health and limiting longstanding illness respectively. The exclusion of these women is only likely to have affected our results if the nonresponders were clustered into few occupational groups.

Second, perceptions of health are sensitive to cultural, psychosocial and other factors, which may be especially relevant to countries in transition. Although a growing number of studies have shown that this measure of self-assessed health is strongly correlated with more objective measures such as mortality, ${ }^{17}{ }^{18}$ and that there is a substantial difference in mortality between Eastern and Western Europe ${ }^{19}$ we should not exclude the possibility of a substantial, additional effect of cultural differences. The most important issue in this regard is whether such differences vary according to class, and whether these class variations are larger in some countries than in others. However, despite such possible variations it is remarkable that the observed class inequalities are so similar across all regions within Europe.

Third, the analysis might be sensitive to the chosen cut-off point of self-assessed general health. We therefore evaluated whether the results for the Eastern region would be sensitive to using the measure "less than fair health" instead of the most commonly applied measure "less than good health". This test (not shown in tables) demonstrated that the ORs based on model 1 (class + age) increased within all regions, except among men in Northern European countries, which also include the United Kingdom and Ireland. Generally, this increase was largest for Central-Western men and South European women (about 30\%), and smallest for the East European populations ( $6 \%$ among women and $16 \%$ for men). However, the observed pattern between the regions did not change with this lower cutoff point; inequalities in health do not appear to be larger in the East than in the other regions. They are of similar size, except for clearly larger inequalities among men in the Central West and women in the South. With one main exception, the proportion of class differences explained by income and education did not change considerably in the four regions. This exception was the Northern region, where the educational contribution decreased among men (10\%) and women (16\%), whereas the income contribution increased among men (18\%).

Fourth, although the ESS presents an outstanding opportunity to investigate cross-national patterns of health inequality, as the survey asks the same questions in all countries, we acknowledge that there are many issues that may affect the comparability of multi-country studies, such as non-response, modes of data collection, translations and conduct. Nonetheless, we believe that the basic finding of our study, which indicates important similarities between countries in class-related health inequalities, would also be observed with data from a survey with perfect comparability.

Fifth, as the aim of the study is to compare regions, we may lose important variations at the country level. We have therefore reported the country-specific odds within welfare regimes for men and women separately (table 4, online). This table shows that there is no evidence for large and systematic variations between the Eastern countries in the magnitude of inequalities, with the only exception of smaller inequalities in Slovenia.

Finally, we performed sensitivity analyses to determine whether the non-response on income is related to health in our study (results not shown). Even though these tests showed that the non-response on income does not seem to be related to health, it is likely that the role of income is underestimated, because for all persons with income unknown, the statistical analysis could not take into account the effect of having a high or low income.

\section{Key findings and their implications}

Our study does not support the hypothesis that East European countries have substantially larger class-related health inequalities than other European regions. This finding does not correspond with previous studies of mortality. In a recent 
review of previous studies on inequalities in Eastern Europe, Mackenbach et al ${ }^{20}$ suggest that during the late 1980s, inequalities in mortality in Eastern Europe were at least as large, and probably much larger than in Western Europe. Martikainen et al ${ }^{4}$ reported larger educational health inequalities in the East (Czech Republic and Estonia) than in the West (Norway and Italy) among women, whereas the educational differences among men were reported to be larger than in the East. ${ }^{4}$ They also reported large and widening mortality gaps in Hungary compared with Western countries (Belgium, Austria, and England and Wales). Another study by Leinsalu et a $t^{5}$ explored a tremendous rise of the mortality gap in Estonia, whereas Leon et $a l^{8}$ reported a reduction in educational mortality differences in the Czech Republic (and Finland) and a striking increase in Estonia and Russia.

The only previous study that is similar to ours because of its focus on morbidity instead of mortality is the one by Knesebeck et $a l^{11}$ Although they did not explicitly compare morbidity differences in the East with those in the West, they analysed both West and East European countries. They applied the same health indicators and the same cut-off points from the ESS as the present study, but used the educational level as the indicator of socioeconomic position. From their tables, it seems that inequalities are generally large in the East. They stated that the inequalities are relatively large in Hungary, Poland and Portugal and small in Austria, Norway, Sweden and the United Kingdom. This is not consistent with our findings. The first possible reason for the diverging results is due to sample differences. Knesebeck et al ${ }^{11}$ only used the first wave of the ESS, which provided the study with half of the cases and fewer countries (Slovakia and Estonia were not included). Second, it might also be because education is a stronger predictor for health in East than occupational class.

This comparison with previous studies raises the key question why inequalities are larger in the East with regard to mortality but not for morbidity. The answer may be related to factors that could have affected the lower classes in the East more than in the West with regard to mortality, but not for self-assessed health. For example, behavioural patterns, ${ }^{8}$ psychosocial factors ${ }^{21-23}$ and material deprivation ${ }^{9}$ might contribute to mortality selection. ${ }^{20}$ When mortality at younger ages is high, as in the East European countries, it might affect the frail people first, leaving a more selected and more robust population that survives to older ages. This could be a reason why inequalities in mortality are larger in the East, whereas inequalities in morbidity are of similar magnitude as those in the West. Comparisons of ill health by gender in this region support the mortality selection hypothesis, as there seems to be a large toll of premature male mortality in the Russian Federation compared with Western European countries. ${ }^{24}$ It is also likely that social stagnation and disintegration may have contributed to relatively large health inequalities with regard to mortality, but not necessarily with respect to morbidity. Negative experiences of the communist regimes could lead to lower expectations for health and health care, causing less complaints of ill health among people of low education. According to the WHO, the East European countries spend less than Western European countries on health per capita, after controlling for differences in purchasing power. ${ }^{19}$ Although these arguments might appear somewhat speculative, they could point to possible mechanisms that could explain why inequalities are larger in the East with regard to mortality but not for morbidity.

A parallel to our key finding is the mortality-morbidity gender paradox, which is partly explained by the fact that fatal conditions are more frequent among men, and non-fatal

\section{What this study adds}

- This study examines whether class-related health inequalities vary between Eastern and Western (North, Central and South) European populations. Specifically, it examines whether class related self-reported health inequalities are comparatively larger in the East.

- In addition, this study applies the new European Socioeconomic Scheme to describe class-related health inequalities in several European countries.

- We found little evidence for the hypothesis that East European countries would have larger class-related health inequalities than countries in other European regions.

\section{Policy implications}

Making investments in education and reducing the interdependence between income and health could reduce health inequalities in the East, although not to a greater extent than in other European regions.

conditions are more frequent among women. Many of the causes of premature death in Eastern Europe are sudden (cardiac death, injuries and violence, alcoholic poisoning) and are less likely to be associated with preceding ill health. Hence, it is likely that the relationship between poor health and mortality will be attenuated in this region.

We should also keep in mind that the former communist countries emphasised an egalitarian class ideology in the past, which might be still persistent in the occupational structure, but it is difficult to disentangle whether the observed inequalities are due to the historical background or whether it is due to the Eastern countries performing well.

\section{CONCLUSION}

We found little evidence for the hypothesis that East European countries have larger class-related health inequalities than other European regions. The variation in people's educational attainment and income both contribute to the occupational health inequalities in the East as well as in the West. Thus, reducing the effect of education and income on poor health could reduce class-related health inequalities in the East, but not to a greater extent than in other European regions.

Competing interests: None declared.

\section{REFERENCES}

1. Forster DP, Jozan P. Health in Eastern-Europe. Lancet 1990;335:458-60.

2. Guo G. Mortality trends and causes of death - a comparison between Eastern and Western Europe, 1960s-1980s. Eur J Popul 1993;9:287-312.

3. Laaksonen M, McAlister AL, Laatikainen T, et al. Do health behaviour and psychosocial risk factors explain the European East-West gap in health status? Eur J Public Health 2001;11:65-73.

4. Martikainen P, Makela P, Koskinen S, et al. Income differences in mortality: a registerbased follow-up study of three million men and women. Int J Epidemio/ 2001;30:1397-405.

5. Leinsalu M, Vagero D, Kunst AE. Estonia 1989-2000: enormous increase in mortality differences by education. Int J Epidemiol 2003;32:1081-7.

6. Kunst AE, Groenhof F, Anderson 0, et al. Occupational class and ischemic heart disease mortality in the United States and 11 European countries. Am J Public Health 1999;89:47-53.

7. Micklewright J. Education, inequality and transition. Florence: Unicef, 2000.

8. Leon DA, Chenet L, Shkolnikov VM, et al. Huge variation in Russian mortality rates 1984-94: Artefact, alcohol, or what? Lancet 1997;350:383-8. 
9. Bobak M, Marmot M. East-West mortality divide and its potential explanations: Proposed research agenda. BMJ 1996;312:421-5.

10. Carlson P. Self-perceived health in East and West Europe: Another European health divide. Soc Sci Med 1998;46:1355-66.

11. Knesebeck OV, Verde PE, Dragano N. Education and health in 22 European countries. Soc Sci Med 2006;63:1344-51.

12. Mackenbach JP, Stirbu I, Roskam A-JR, et al. Socioeconomic inequalities in health in 22 European countries. N Engl J Med 2008;358:2468-71.

13. Vågerø D, Illsey N. Inequality, Health and policy in East and West Europe. Int $J$ Health Sci 1992; 3:225-39.

14. Eikemo TA, Huisman M, Bambra C, et al. Health inequalities according to educational level in different welfare regimes: a comparison of 23 European countries. Sociol Health IIIn 2008; 30:565-82.

15. Erikson R, Goldthorpe JH. The Constant Flux. Oxford: Clarendon Press, 1992.

16. Hagenaars A, de Vos K, Zaidi MA. Poverty Statistics in the Late 1980s: Research Based on Micro-data. Office for Official Publications of the European Communities. Luxembourg, 1994.
17. Heistaro $\mathbf{S}$, Jousilahti $P$, Lahelma $E$, et al. Self rated health and mortality: a long term prospective study in eastern Finland. J Epidemiol Community Health 2001;55:227-32.

18. Idler EL, Benyamini Y. Self-rated health and mortality: A review of twenty-seven community studies. J Health Soc Behav 1997:38:21-37.

19. World Health Organisation. http://www.WHO.org.Please

20. Mackenbach J. Health Inequalities: Europe in Profile. An independent, expert report commissioned by, and published under the auspices of, UK Presidency of the EU 2006.

21. Hertzman C, Kelly S, Bobak M. East-West Life Expectancy Gap in Europe. Environmental and Non-environmental Determinants. Dordrecht: Kluwer, 1996.

22. Kristenson M, Kucinskiene Z, Bergdahl B, et al. Increased psychosocial strain in Lithuanian versus Swedish men: The LiVicordia study. Psychosom Med 1998:60:277-82

23. Watson P. Explaining Rising Mortality among Men in Eastern-Europe. Soc Sci Med 1995:41:923-34.

24. Andreev EM, McKee M, Shkolnikov VM. Health expectancy in Russia: a new perspective on the health divide in Europe. Bull World Health Organ 2003;81:778-88.

\section{Quality \& Safety in Health Care}

Quality \& Safety in Health Care is a leading international peer-review journal in the growing area of quality and safety improvement. It provides essential information for those wanting to reduce harm and improve patient safety and the quality of care. The journal reports and reflects research, improvement initiatives and viewpoints and other discursive papers relevant to these crucial aims with contributions from researchers, clinical professionals and managers and experts in organisational development and behaviour.

qshc.bmj.com

Quality

\&Safety in 